\title{
6. Themenbereich somatische Gentherapie: aus dem Labor über klinische Studien zum kommerziellen Einsatz
}

\subsection{Die Gentherapie weiter auf dem Vormarsch}

Die Geschichte der Gentherapie, die vielen Vorschusslorbeeren, die kleinen Erfolge und die großen Rückschläge wurden in den vorigen Gentechnologieberichten sowie den beiden Themenbänden der interdisziplinären Arbeitsgruppe (IAG) Gentechnologiebericht zur somatischen Gentherapie ausführlich dargestellt. ${ }^{1}$ Anfang der 2010er Jahre gelang der somatischen ${ }^{2}$ Gentherapie endlich der lang ersehnte, nicht nur in Fachkreisen, sondern auch in der breiten Öffentlichkeit als Durchbruch wahrgenommene Therapierfolg: Patienten mit Blutkrebs, der auf keine der existierenden Behandlungen mehr ansprach, konnten durch die Infusion sog. CAR-T-Zellen ${ }^{3}$ ihre Krebserkrankung erneut langfristig oder zumindest zeitweise im Schach halten. Im 4. Gentechnologiebericht hatten wir die Frage gestellt, ob sich dieses Comeback der Gentherapie weiter konsolidieren und als nachhaltig erweisen würde. Diese Frage kann, vor allem mit Blick auf die internationale

1 Hucho et al. (2005), Müller-Röber et al. (2009), Müller-Röber et al. (2015), Hucho et al. (2018); Fehse et al. (2011), Fehse/Domasch (2015).

2 "Somatisch“ bedeutet ,an Körperzellen“. Der Begriff „somatische Gentherapie“ wird mit dem Ziel der Abgrenzung von möglichen Ansätzen der Keimbahnmodifikation benutzt. Letztere sind vererbbar.

3 „CAR“ steht für „chimäre Antigenrezeptoren“. Die T-Zelle benutzt für die Erkennung der Tumorzellen einen gentechnisch zusammengefügten artifiziellen Rezeptor, bei dem die Antigenbindedomäne eines T-Zell-Rezeptors (TCR) durch deren Pendant eines monoklonalen Antikörpers ersetzt wurde (das sog. single-chain variable fragment, scFv, am ehesten wohl als Einzelketten-Antikörper zu übersetzen). Die Entwicklung der CAR-T-Zellen geht auf Arbeiten Ende der 1980er/Anfang der 1990er Jahre zurück (Gross et al., 1989); der klinische Durchbruch gelang erst 20 Jahre (Grundlagenforschung) später mit den CARs der 2. Generation. Inzwischen werden auch CARs der 3. und 4. Generation klinisch getestet. 
Entwicklung, derzeit mit einem klaren "Ja“ beantwortet werden. Dies betrifft zuvorderst die seit Jahren häufigste Indikation der Gentherapie, nämlich Krebserkrankungen, für die in den letzten Jahren neben einer Vielzahl klinischer Studien auch mehrere Zulassungen zu verzeichnen waren. Zugleich gab es aber auch sehr große Fortschritte bei Gentherapien für monogene Erbkrankheiten - ebenfalls widergespiegelt sowohl durch die steigende Zahl an klinischen Testungen als auch mehrere, zum Teil aufsehenerregende Marktzulassungen. Die deutlich schnellere und breitere Entwicklung der Gentransfertechnologien, nicht zuletzt durch die neuen Möglichkeiten des gezielten Genome-Editing (Stichwort CRISPR/Cas, siehe Fehse et al., Kap. 9), ${ }^{4}$ führte zu einem gewaltigen Schub bei der Erforschung gentherapeutischer Ansätze in einer ganzen Reihe weiterer Anwendungsfelder wie z. B. Infektionskrankheiten (u. a. HIV).

Eine Infektionskrankheit war es auch, die nicht nur unser aller Leben in den Jahren 2020 und 2021 weitgehend bestimmte, sondern auch das Potenzial gentherapeutischer Technologien in eindrucksvoller Manier aufzeigte (zur aktuellen Impfstoffentwicklung siehe Korte, Kap. 19). Es geht natürlich um die SARS-CoV-19-Pandemie, deren Auswirkungen Anfang 2020, als das neue Coronavirus Europa erreichte, kaum mehr hätten unterschätzt werden können. Unter denen, die die potenziellen Folgen der Pandemie sehr früh verstanden, waren auch Uğur Şahin und Özlem Türeci, die Gründer und Köpfe hinter der Mainzer Firma BioNTech. Bis vor kurzem war diese Firma nur Insidern bekannt - das Tätigkeitsfeld fokussierte auf die Entwicklung neuartiger Immun-/Gentherapien gegen Krebs. Einer der Ansätze beruht auf der Immunisierung von Krebspatienten mit sog. mRNA (,messenger RNA“, deutsch: Boten-RNA), ${ }^{5}$ die patientenspezifisch für solche Eiweiße kodieren, die im Zuge der malignen (bösartigen) Entartung in den Krebszellen des Patienten verändert wurden und daher vom Immunsystem als „fremd“ erkannt werden können. Bisherige Studien mit diesem Prinzip erbrachten vielversprechende Ergebnisse - infolge der Impfung wurden bei vielen Krebspatienten

4 In der ersten und heute verbreitetsten Form basiert das Genome-Editing auf sog. Genscheren oder Designernukleasen. Aufgrund seiner einfachen Herstellung und Anwendung ist das CRISPR/Cas-System bei Weitem am gebräuchlichsten. CRISPR steht für „Clustered regularly interspaced short palindromic repeats“, „Cas“ für „CRISPR-associated [protein]“. Mehr zur Biologie und zur möglichen Anwendung des Genome-Editing in der somatischen Gentherapie: Fehse/Abramowski-Mock (2021).

5 Die mRNA stellt eine Kopie des proteinkodierenden Bereichs eines Gens dar. Diese Kopie wird aus dem Zellkern ausgeschleust und von den Eiweißfabriken der Zelle (den Ribosomen) als Vorlage für die Herstellung der Proteine benutzt. Die Kopie hat in der Zelle nur eine kurze Lebenszeit; da sie ein anderes chemisches Molekül (RNA) als unsere Erbsubstanz (DNA) darstellt, kann sie auch nicht ins Genom eingebaut werden. Als Analogie aus dem IT-Bereich könnte vielleicht ein schnell verbleichender Ausdruck eines Files dienen - die Information auf dem Ausdruck stellt zwar eine Kopie der auf der Festplatte gespeicherten Information dar, kann diese aber nicht modifizieren. 
zum Teil starke Immunreaktionen gegen die Krebszellen ausgelöst (siehe unten). Die BioNTech-Wissenschaftler, die das Prinzip in den letzten Jahren immer weiter optimiert hatten, erkannten sehr schnell, dass eine solche mRNA-basierte Impfung auch gegen das Coronavirus helfen könnte. Basierend auf dieser Hypothese fassten die Leiter einer vergleichsweise kleinen Immun-/Gentherapiefirma einen beeindruckenden und folgenschweren Entschluss - sie setzten mit voller Kraft auf die Entwicklung eines Vakzins. Angesichts der seinerzeit noch wenig bekannten Virusbiologie und natürlich der schier übermächtigen Konkurrenz durch große, in der Vakzinforschung und -entwicklung erfahrene Firmen war zu jenem Zeitpunkt weder ausgemacht, dass der Impfstoff funktionieren, noch, dass die (kommerzielle) Entwicklung im notwendigen globalen Maßstab gelingen würde. ${ }^{6}$ Tatsächlich waren der BioNTech-Impfstoff sowie ein parallel von der Firma Moderna entwickeltes alternatives mRNA-Vakzin die ersten, die in den westlichen Ländern eine Zulassung bekamen - noch vor klassischen wie auch Vektorimpfstoffen. Noch wichtiger aber: das BioNTech-Vakzin zeigte eine kaum zu erwartende, extrem hohe Wirksamkeit von >95 \%. Die ähnlich hohe Effizienz des parallel von Moderna entwickelten mRNA-Vakzins deutet daraufhin, dass der neue mRNA-Ansatz den klassischen Impfstoffen prinzipiell überlegen sein könnte. Unabhängig davon, ob sich mRNA-basierte Vakzine in Zukunft auf breiter Front durchsetzen, war ihre schnelle Entwicklung und vor allem die exzellente Wirksamkeit und Sicherheit von entscheidender Bedeutung dafür, dass schon im Jahr 2021 umfassende Vakzinierungsprogramme möglich wurden. Hier hat eine Technologie, die originär für die Immungentherapie entwickelt wurde, einen kaum zu überschätzenden Beitrag geleistet, um einer der aktuell schwersten Herausforderungen für die globale Gesundheit endlich entgegentreten zu können!

Im Folgenden soll schwerpunktmäßig auf aktuelle Fortschritte, vor allem in der Krebsgentherapie und bei der Behandlung monogener Erbkrankheiten, näher eingegangen werden.

\subsection{Krebsgentherapie}

Die Anwendung gentherapeutischer Prinzipien zur Behandlung maligner Erkrankungen in der Hämatologie/Onkologie nimmt stetig weiter zu. Dabei wird eine Reihe völlig unterschiedlicher Ansätze verfolgt. Die derzeit erfolgreichsten Strategien setzen nicht beim Tumor an, sondern versuchen, Immunzellen durch genetische Veränderung gegen die Tumorzellen „scharf“ zu machen. Auch dafür gibt es, neben den schon oben

6 Zu diesem Zweck verbündete sich BioNTech mit dem amerikanischen Pharmariesen Pfizer. 
eingeführten CAR-T-Zellen, verschiedene Möglichkeiten, auf die in 6.2.1 eingegangen wird. Die in 6.2.2 beschriebenen Gentherapiestrategien zielen dagegen auf eine direkte Zerstörung des Tumors, z. B. durch das Einbringen sog. „Suizidgene“ oder durch die gezielte Infektion mit spezifischen, tumorzerstörenden („onkolytischen“) Viren.

\subsubsection{Immuntherapie mit genetisch modifizierten Zellen}

Der enorme Aufschwung der Immungentherapie lässt sich allein anhand der Zahl klinischer Studien mit CAR-T-Zellen aufzeigen - das internationale Studienregister clinicaltrials.gov verzeichnet aktuell mehrere Hundert laufende klinische Studien mit solchen Zellen. ${ }^{7}$ Diese Anzahl ist umso eindrucksvoller, wenn man sich vor Augen führt, dass bis in die 2010er Jahre jährlich insgesamt nur ca. 100 klinische Gentherapiestudien (in allen möglichen Feldern der Medizin) durchgeführt wurden (vgl. Fehse/Domasch, 2015: 61). Zudem sind bereits mehrere CAR-T-Zell-Produkte kommerziell verfügbar oder stehen unmittelbar vor ihrer Produktzulassung. ${ }^{8}$

Die ersten und bis heute überzeugendsten Erfolge mit CAR-T-Zellen wurden bei Krebsarten erreicht, die auf die maligne Entartung bestimmter Immunzellen, sog. B-Lymphozyten (kurz B-Zellen), zurückgehen. Daher sollen Chancen und Risiken der Nutzung dieser neuen Therapieform vor allem anhand dieser spezifischen Erkrankung etwas näher beleuchtet werden.

Besagte bösartige B-Zell-Erkrankungen (Lymphome sowie akute und chronische BZell-Leukämien) zeichnen sich dadurch aus, dass in der Regel alle entarteten B-Zellen spezifische Eiweißmoleküle („Antigene“) auf ihrer Zelloberfläche tragen, die auch für gesunde B-Zellen charakteristisch sind. Die besonders hohe Wirksamkeit von CAR-TZellen bei B-Zell-Erkrankungen liegt somit offensichtlich nicht zuletzt darin begründet, dass besagte Antigene sehr wichtig für das Überleben selbst maligner B-Zellen sind. Schon die allerersten erfolgreichen Studien (mit nur wenigen Patienten) zeigten, dass sich einer dieser „B-Zell-Marker“, CD19, besonders für die Therapie mit CAR-T-Zellen eignet (Kalos et al., 2011; Porter et al., 2011; Grupp et al., 2013). Erfreulicherweise konnten die dort erzielten ausgezeichneten Ergebnisse sehr schnell auch durch andere Gruppen und schließlich in relativ großen kontrollierten klinischen Studien bestätigt werden (Neelapu et al., 2017; Schuster et al., 2019). Im Zuge der Studien wurden neben einer exzellenten Wirksamkeit auch völlig neuartige Nebenwirkungen der CAR-T-Zellbasierten Immuntherapie registriert, die u. a. darauf beruhen, dass die CAR-T-Zellen

7 Siehe unter: www.clinicaltrials.gov (Suchwort: „chimeric antigen receptors“) [28.01.2021].

8 In der EU sind (Stand Februar 2021) zwei CD19-CAR-T Produkte zugelassen: Tisagenlecleucel $\left(\mathrm{Kymriah}^{\circledast}\right)$ sowie Axicabtagene Ciloleucel (Yescarta $\left.{ }^{\circledR}\right)$; in den USA bereits vier. 
sich im Körper des Patienten in kurzer Zeit (in der Regel in 7-10 Tagen) sehr stark vermehren und dann ,überfallartig“ die nicht selten sehr großen Tumoren ${ }^{9}$ angreifen und zerstören (Lee et al., 2019). Mit dieser massiven Aktivierung des Immunsystems geht bei vielen Patienten ein sog. Zytokinsturm (CRS) ${ }^{10}$ einher, der bei starker Ausprägung den gesamten Kreislauf aus dem Gleichgewicht bringen kann. Zum Glück wurden sehr schnell Wege gefunden, diesen Sturm durch geeignete Gegenmittel zu beruhigen, ohne dabei die erwünschte Immunantwort gegen den Tumor zu unterdrücken. Neben dem bei den meisten Patienten (in unterschiedlicher Ausprägung) auftretenden Zytokinsturm zeitigten die CAR-T-Zell-Infusionen bei etwa der Hälfte der Patienten eine unerwartete Neurotoxizität, deren Ursachen bis heute nicht komplett verstanden sind. ${ }^{11}$ Auch die Neurotoxizität lässt sich glücklicherweise durch eine geeignete Behandlung bei der übergroßen Mehrheit der Patienten sehr schnell und komplett beseitigen. Schließlich entwickelt ein Teil der Patienten nach der CAR-T-Zell-Behandlung eine relativ lange Phase der Blutarmut. Diese Nebenwirkung ist wahrscheinlich zumindest zum Teil darauf zurückzuführen, dass die Krebspatienten, die bisher für eine CAR-Therapie infrage kommen, eine lange Krankheitsgeschichte mit oft sehr vielen Chemotherapien hinter sich haben, sodass ihre Blutbildungsreserven schon stark eingeschränkt sind. ${ }^{12}$

Schließlich haben CD19-CAR-T-Zellen auch eine „logische“ Nebenwirkung, die als „on-target off-tumor“-Toxizität bezeichnet wird: Da das Zielantigen CD19 ja auch auf gesunden B-Zellen exprimiert wird, werden auch diese Zellen von den CAR-T-Zellen eliminiert. Tatsächlich kann man, wenn man keine Möglichkeit hat, die CAR-T-Zellen direkt im Blut nachzuweisen, indirekt auf ihre Anwesenheit und Funktionalität schließen: Solange die CD19-CAR-T-Zellen „ihren Job erledigen“, wird der Patient keine BZellen haben - weder bösartige, noch gesunde. Umgekehrt zeigt die Wiederkehr der gesunden B-Zellen, dass die CAR-T-Zellen verloren gegangen (oder nicht mehr funktio-

9 Die bösartigen B-Zellen vermehren sich z. B. in den Lymphknoten und bilden dort Tumoren (Lymphome).

10 Eigentlich Zytokinfreisetzungssyndrom bzw. englisch „Cytokine release syndrom“ (CRS).

11 „Immune-cell associated neurotoxicity syndrome“ (ICANS): z. B. Schreib- und Sprachstörungen, Verwirrtheit, Krampfanfälle u. Ä. ICANS tritt vor allem bei Behandlung mit CD19-CAR-T-Zellen auf. Neue Daten deuten darauf hin, dass dies an einer schwachen Expression des CD19-Moleküls in bestimmten Stützzellen der Blutgefäße im Gehirn (sog. murale Zellen) liegen könnte (Parker et al., 2020). Damit würde es sich um eine nur schwer vermeidbare „on-target off-tumor“-Toxizität handeln (siehe Text).

12 Die Chemotherapien können die Blutbildungsreserve in doppelter Hinsicht schädigen - zum einen wird die Zahl an Blutstamm- und Vorläuferzellen verringert, zum anderen kann auch das Stroma im Knochenmark geschädigt werden, welches die für eine effiziente Vermehrung der Zellen notwendige Umgebung (Nische) bildet. Möglicherweise haben auch die CAR-T-Zellen und/oder das CRS einen negativen Effekt auf das Stroma. 
nell) sind. Aus dieser Nebenwirkung, dem Verlust der gesunden B-Zellen, ergibt sich die Frage, ob (bzw. wie gut) ein Mensch ohne B-Lymphozyten leben kann, die ja ein wichtiger Teil unseres adaptiven Immunsystems sind. ${ }^{13}$ Die offensichtliche Antwort ist eine der wichtigsten Grundlagen für den Erfolg der CD19-CAR-T-Zellen - der Verlust von B-Zellen kann durch entsprechende Behandlung weitgehend kompensiert werden. Wichtig ist dabei auch die Tatsache, dass die aus „reifen“ (also antigenspezifischen) B-Zellen entstandenen, antikörperproduzierenden Plasmazellen kein CD19 mehr auf der Oberfläche tragen. Dies bedeutet, dass die CAR-T-Zellen bereits bestehende, durch Infektion oder Impfungen erworbene B-Zell-Immunität nicht beeinflussen. Lymphome, welche die wichtigste Indikation für eine CD19-CAR-T-Zell-Behandlung darstellen, treten fast nur bei älteren Patienten auf, deren bereits bestehende breite Antikörper-Immunantwort gegen sehr viele Erreger entsprechend auch bei vollständigem Verlust der B-Zellen erhalten bleibt. Neuere Daten legen zudem nahe, dass bei Lymphompatienten eine einmal erreichte vollständige Remission, bei der Tumorzellen sich im Körper nicht mehr nachweisen lassen, oft auch nach einem Verlust der CAR-T-Zellen erhalten bleibt. Etwas anders sieht die Situation bei akuten-B-Zell-Leukämien aus, hier ist Verlust der CAR-T-Zellen prognostisch zumeist ungünstig. Von dieser, glücklicherweise sehr seltenen, Krankheit sind eher Kinder und Jugendliche betroffen, bei denen sich noch vergleichsweise wenige B-Lymphozyten zu Plasmazellen ausdifferenziert haben. Infolge des Fehlens der B-Zellen können junge, mit CD19-CAR-T-Zellen behandelte Patienten auch keine neuen, antikörperproduzierenden Plasmazellen ausbilden, die eine aktuelle Infektion bekämpfen bzw. sie vor einer zukünftigen Infektion mit denselben Erregern schützen würden. Zum Glück kann den Betroffenen aber geholfen werden: Da einmal produzierte Antikörper relativ lange (mehrere Monate) im Blut stabil sind, besteht die Möglichkeit, diese aus dem Blut gesunder, freiwilliger Spender zu isolieren und Patienten mit B-Zell-Mangel zu transfundieren. ${ }^{14}$ Zwar lässt sich die B-Zell-Immunität auf diese Weise nicht komplett ersetzen, aber es kann doch ein akzeptables Maß an Infektionsschutz gewährleistet werden.

13 Das Immunsystem umfasst zwei Ebenen - die angeborene, unspezifische Immunantwort und die adaptive, spezifische Immunabwehr. Letztere basiert auf den T- und B-Lymphozyten, die über spezielle Rezeptoren auf ihrer Oberfläche neue, in den Körper eingedrungene Fremdantigene erkennen können. Passende B-Zell-Rezeptoren werden, z. B. im Zuge einer Virusinfektion (oder nach einer Impfung), perfekt an die Antigene des Eindringlings angepasst. Ist dies erfolgt, reifen die B-Zellen zu antikörperproduzierenden Plasmazellen. Die Antikörper inaktivieren die Viren, sodass die Infektion unterdrückt wird.

14 Solche Infusionen, sog. Immunglobuline, werden seit vielen Jahren auch bei anderen B-Zell-Defizienzen angewendet, sowohl angeborenen als auch erworbenen Immunmangelkrankheiten (z. B. AIDS). 
Zusammengenommen sind es diese beiden Faktoren die erklären, dass es gerade die malignen B-Zell-Erkrankungen waren, bei denen der Durchbruch mit CAR-T-Zellen erzielt wurde. Nicht nur, dass das CD19-Antigen, wie oben beschrieben, selbst für das Überleben entarteter B-Zellen sehr wichtig zu sein scheint, B-Lymphozyten gehören darüber hinaus zu den nur sehr wenigen Zellarten im Körper, deren Totalverlust durch geeignete Therapien in ausreichendem Maße kompensiert werden kann. Umgekehrt bedeutet dies, dass man nicht per se davon ausgehen kann, dass sich der Erfolg mit den CD19-CAR-T-Zellen auch bei anderen Krebsarten vollumfänglich reproduzieren lässt. Dies ist natürlich insbesondere dann relevant, wenn das Antigen, gegen das sich die CAR-Zellen richten, auch von gesunden Zellen exprimiert wird. Z. B. kann ein Mensch zwar über lange Zeiten ohne B-Lymphozyten, praktisch aber nicht ohne deren „Cousins“, die T-Lymphozyten, leben, da das Fehlen von T-Zellen mit einem sehr schweren Immunmangelsyndrom einhergeht, welches medikamentös nicht kompensiert werden kann. Zur Behandlung von T-Zell-Leukämien (wie auch vieler anderer Krebserkrankungen) müssen daher spezifische, oft ausgefeilte Konzepte der Anwendung von CAR-TZellen entwickelt werden (siehe unten).

Anhand der inzwischen sehr umfangreichen klinischen Erfahrungen vor allem mit CD19-CAR-T-Zellen lässt sich konstatieren, dass die Anwendung von CAR-T-Zellen mit großen Chancen, aber auch mit signifikanten Nebenwirkungen verbunden ist, die oft einer intensivmedizinischen Behandlung bedürfen. Das bedeutet, dass besagte Therapien bis auf weiteres nur in einem geeigneten klinischen Umfeld möglich sind, um die höchstmögliche Wirksamkeit wie auch Patientensicherheit zu gewährleisten. Die deutschen Fachverbände sind sich einig, dass dies nicht nur die notwendige Infrastruktur, sondern vor allem auch ein multidisziplinäres Team aus erfahrenen Stammzelltransplanteuren, Hämatologen, Onkologen, Organspezialisten, Intensivmedizinern, Neurologen, Transfusionsmedizinern sowie Transplantkoordinatoren umfasst (Ayuk et al., 2019). Auch unter Berücksichtigung der Nebenwirkungen können die mit den CD19-CAR-T-Zellen erreichten Therapieergebnisse angesichts der Schwere der bestehenden therapieresistenten Krebserkrankung als ausgezeichnet zusammengefasst werden (Jain/Davila, 2018). Dies hatte auch dazu geführt, dass die US-amerikanische Zulassungsbehörde FDA zwei der oben erwähnten CAR-T-Präparate (siehe Fußnote 9) bereits im Jahr 2017 im Schnellverfahren für die kommerzielle Anwendung zuließ. Die Zulassung der beiden Therapien in der EU durch die EMA (European Medicines Agency) erfolgte im darauffolgenden Jahr. Danach kam es zur relativ breiten klinischen Anwendung von CD19-CAR-T-Zellen auch in Deutschland, vor allem in universitären Zentren. Aus diesen Arbeiten resultierten bereits wichtige Erkenntnisse zur „real-world“-An- 
wendung von CAR-T-Zellen (u. a. Ayuk et al., 2021; Rejeski et al., 2021). Inzwischen ist in den USA eine weitere CD19-CAR-Therapie lizenziert.

Der durchschlagende Erfolg der CAR-T-Zellen bei den vergleichsweise seltenen BZell-Leukämien und -Lymphomen führte schnell zur Entwicklung und klinischen Testung weiterer CAR-Konstrukte, sowohl für andere hämatologische wie auch für solide Tumorerkrankungen. ${ }^{15}$ Im Bereich der hämatologischen Krebserkrankungen werden mit der Entwicklung neuer CAR-Konstrukte mehrere Ziele verfolgt. Bei den malignen B-Zell-Erkrankungen geht es vor allem darum, die nachgewiesene Wirksamkeit weiter zu verbessern. Auch wenn die Mehrheit der Patienten durch die CAR-T-Zell-Behandlung eine oft vollständige Unterdrückung der Krebszellen erreicht, ist diese komplette Remission nur bei einem Teil der Patienten von langer Dauer. Einige Patienten „verlieren“ die CAR-T-Zellen (oft weil die CARs als immunologisch fremd ${ }^{16}$ und damit „feindlich“ erkannt werden) oder deren Aktivität; bei anderen schaffen es die Krebszellen, sich für die CAR-T-Zellen unsichtbar zu machen, indem sie sich des CD19-Antigens entledigen. Bei neueren CAR-Konstrukten wird auf verschiedenen Wegen versucht, diesen Verlust an Wirksamkeit von vornherein zu verhindern. So werden z. B. CAR-Konstrukte eingesetzt, bei denen der Antikörperanteil von einem humanen Antikörper abgeleitet wurde, immunologisch also nicht als fremd erkannt wird. Auch gibt es Versuche, mithilfe des Genome-Editing bestimmte Bremsen (sog. ,immune checkpoints“) aus den CAR-T-Zellen auszubauen, welche von den Tumorzellen genutzt werden, um die T-Zellen in einen Dornröschenschlaf zu versetzen. Schließlich laufen Studien, bei denen die CAR-T-Zellen sich gleich gegen zwei Antigene auf der Oberfläche der bösartigen Zellen richten. ${ }^{17}$ Die Zellen werden dazu entweder mit zwei CAR-Konstrukten ausgestattet oder auch einem CAR, der gleich über zwei Erkennungsdomänen verfügt. Andere Forschungsarbeiten, nicht zuletzt in Deutschland, versuchen über alternative Vektorplattformen wie Transposons ${ }^{18}$ die Herstellung von CAR-T-Zellen einfacher zu machen (Monjezi et al., 2017; Prommersberger et al., 2021).

15 Die Hämatologie beschäftigt sich mit malignen Erkrankungen, die aus Blutzellen hervorgehen, die Onkologie mit solchen, die in „festen“ Geweben entstehen (=,,solide Tumoren“).

16 Bei der ersten Generation der CARs wurde der Antikörperanteil von einem Mausantikörper abgeleitet.

17 Bei B-Zell-Erkrankungen z. B. gegen CD19 und CD20. Diesem Prinzip folgt $u$. a. eine Studie der deutschen Firma Miltenyi Biomedicine; siehe unter: https://clinicaltrials.gov/ct2/show/NCT03870945 [10.02.2021].

18 Vektorplattformen sind die Genfähren oder Gentaxis, die die Gene in die Zellen einbringen. Häufig sind dies entschärfte Viren. Es können jedoch auch Transposons, also springende Gene sein. Dies sind DNA-Sequenzen mit der Fähigkeit, die eigene Position im Genom zu verändern, was als Transposition bezeichnet wird. 
Die bei den B-Zell-Erkrankungen gewonnenen Erkenntnisse helfen dann natürlich auch bei der Entwicklung von CARs für andere Krebsarten. Im Feld der Hämatologie sind vor allem die Studien für das Multiple Myelom (MM) ${ }^{19}$ weit fortgeschritten. Beim MM laufen aktuell (vor allem in China und den USA) mehr als 50 klinische Studien mit CAR-T-Zellen, wobei verschiedene Antigene als Zielstrukturen getestet werden (Gagelmann et al., 2020). ${ }^{20}$ Hier wird noch im Laufe des Jahres 2021 mit einer ersten Zulassung für BCMA-gerichtete CAR-T-Zellen auch in der EU gerechnet. Auch bei der akuten myeloiden Leukämie (AML) werden CAR-T-Zellen in Dutzenden klinischer Studien getestet. Da die von den CAR-T-Zellen erkannten Antigene auf AML-Zellen (z. B. CD33, CD123) auch auf gesunden blutbildenden Zellen zu finden sind, werden hier verschiedene Tricks angewandt, um die oben eingeführte On-target-off-tumor-Toxizität zu verhindern. Ein zuvorderst von deutschen Wissenschaftlern entwickeltes, sehr spannendes Prinzip beruht darauf, die CARs kurzfristig an- und abschalten zu können. Dazu werden die T-Zellen quasi mit einem halben CAR-Molekül ausgestattet, das zwar über die Teile zur Aktivierung der T-Zelle verfügt, bei dem aber der essenzielle Teil zur Antigenerkennung (der Einzelkettenantikörper) durch einen universellen Adapter ersetzt wurde. ${ }^{21}$ An diesen Adapter können dann die spezifischen tumorerkennenden (Antikörper-)Moleküle über ein Schlüssel-Schloss-Prinzip binden. Dieser Ansatz hat mehrere potenzielle Vorteile, u. a. den, dass mit denselben CAR-T-Zellen gleichzeitig oder nacheinander verschiedene Antikörper gekoppelt werden können. Sollten die CAR-TZellen unerwünscht Nebenwirkungen verursachen, sind sie sehr schnell abschaltbar, indem kein Antikörper mehr infundiert wird.

Während die meisten hämatologischen Krebserkrankungen sehr selten und zudem heute oft schon gut behandelbar sind, zählen einige solide Tumoren (wie Brust-, Lungen- oder Prostatakrebs) zu den globalen Haupttodesursachen. Daher ist es nicht verwunderlich, dass der Erfolg der CAR-T-Zellen auch auf sehr großes Interesse in der Onkologie gestoßen ist. Dies hat zu einer ganzen Reihe klinischer Studien zur Behandlung unterschiedlichster Tumoren mit CAR-T-Zellen geführt (Moreno-Cortes et al., 2021).

19 Beim MM geht der Krebs auf sog. Plasmazellen zurück. Dabei handelt es sich um gewebeständige, ausgereifte B-Zellen, die als Teil der langfristigen Immunantwort jeweils einen spezifischen Antikörper produzieren.

20 Z. B. BCMA („B-cell maturation antigen“), CD19, CD38 und SLAMF7/CS1. Bei einigen Studien werden bereits zwei Antigene gleichzeitig adressiert. In den USA wurde Ende März 2021 eine erste BCMAgerichtete CAR-T-Zell-Therapie lizenziert.

21 Das Prinzip wird von zwei deutschen Firmen für die klinische Anwendung entwickelt. Die Firma Cellex nennt ihre Methode „UniCAR“ (universeller CAR) und führt bereits eine klinische Studie mit dem UniCAR02-T-CD123 durch; siehe unter: https://clinicaltrials.gov/ct2/show/NCT04230265 [10.02.2021]. Die Firma Miltenyi Biomedicine entwickelt unter dem Namen „Adapter CAR“ ein alternatives Konstrukt. 
Allerdings ist die Biologie solider Tumoren um einiges komplexer - sie akquirieren im Laufe ihrer Entstehung im Vergleich mit hämatologischen Neoplasien deutlich mehr Mutationen und sind daher zum Zeitpunkt der Diagnose oft schon sehr heterogen, bestehen also aus einer Vielzahl von Subklonen mit leicht unterschiedlichen Eigenschaften. Dies führt schon bei den klassischen Therapieverfahren dazu, dass einige dieser Subklone eine Resistenz entwickeln können (oder bereits aufweisen), die es ihnen ermöglicht, die zytotoxische Therapie zu überleben. Durch die große Heterogenität ist es zugleich schwierig, geeignete tumorspezifische oder zumindest tumorassoziierte Antigene zu finden, die auf der Oberfläche möglichst aller Tumorzellen vorhanden sind. Tumorspezifische Antigene (TSA) werden ausschließlich von Tumor-, nicht aber von gesunden Zellen exprimiert. Solche Antigene treten in den sehr seltenen Fällen auf, wenn das Neo-Antigen direkt für den Tumor verantwortlich ist. ${ }^{22}$ Bei den meisten bösartigen Erkrankungen führen kleine Mutationen in regulatorischen Gene und/oder die Abschaltung sog. Tumorsuppressorgene zur malignen Transformation. Solche Veränderungen sind für CARs zumeist nicht erkennbar. ${ }^{23}$

Deutlich häufiger als TSAs sind tumorassoziierte Antigene (TAAs), die in bösartigen, aber auch gesunden Zellen vorkommen. ${ }^{24}$ TAAs eignen sich als Zielstrukturen für die Immuntherapie, wenn die Toxizität, welche durch die oben schon angesprochene On-target-off-tumor-Aktivität vermittelt wird, relativ gering ist bzw. durch geeignete therapeutische Maßnahmen (wie bei den B-Zellen, siehe oben) in Grenzen gehalten werden kann. Besonders interessant unter den TAAs sind von Krebszellen exprimierte Antigene, die zwar auch in gesunden Zellen vorkommen, aber normalerweise nur in der frühen Embryonalentwicklung. ${ }^{25}$ Für die Immuntherapie sehr wichtig ist der Umstand, dass die meisten TAAs nicht auf der Zelloberfläche, sondern im Zellinneren zu finden sind. Dies bedeutet, dass sie sich nicht für CAR-, sondern nur für TCR-basierte Therapien eignen (siehe unten).

Weitere Herausforderungen für die zelluläre Immuntherapie ergeben sich aus der Struktur solider Tumoren. Ein Tumor ist zumeist viele Jahre in Wechselwirkung mit den umgebenden Geweben gewachsen. Durch den oft kompakten Aufbau sind viele Tumorzellen, zumal die Stammzellen, die das Wachstum des Tumors befeuern, oft für die Immunzellen nicht erreichbar. Dieses Problem wird noch dadurch verstärkt, dass Zellen im Innern von Tumoren oft wegen schlechter Versorgung absterben, sodass

22 Dies kann z. B. bei veränderten, dauerhaft aktiven Wachstumsrezeptoren der Fall sein.

23 Nicht wenige solcher kleinen Veränderungen können aber im Prinzip durch die T-Zell-Rezeptoren (TCRs) detektiert werden (siehe unten).

24 CD19 (wie auch CD20 und CD22) wären typische TAA.

25 Sog. onkofötale Antigene, wie z. B. Cancer-testis Antigene. 
sich Flüssigkeit ansammelt. Im Innern des Tumors entsteht dadurch ein relativer Überdruck, der eine physikalische Barriere gegen das Eindringen von Immunzellen aufbaut. Schließlich haben Tumoren es oft geschafft, um sich herum ein immunsuppressives Milieu (sog. „immunosuppressive tumor microenvironment“) zu etablieren. Diese, zusammen mit den o. g. Faktoren sind ursächlich dafür, dass die CAR-T-Zell-Therapien für solide Tumoren bisher deutlich weniger erfolgreich sind als bei hämatologischen Krebserkrankungen (Arcangeli et al., 2020; Wagner et al., 2020).

Es wird eine Reihe von Forschungsansätzen verfolgt, um die Effizienz der CAR-TZellen bei soliden Tumoren zu erhöhen. So wurden spezielle CAR-Konstrukte der 4. Generation entwickelt, die in den genetisch modifizierten T-Zellen zusätzlich zur CAR-Expression die Produktion immunstimulatorischer Faktoren induzieren. Dadurch sollen weitere Immunzellen angelockt und das vom Tumor aufgebaute immunsuppressive Milieu durchbrochen werden. Wichtige Arbeiten zur Entwicklung solcher weiterentwickelten CAR-Konstrukte kommen von einem der führenden CAR-Forscher aus Deutschland, Hinrich Abken, der für diese auch den Namen TRUCKs geprägt hat. ${ }^{26}$

Neben ihren Vorteilen haben CARs auch einige spezifische Nachteile. Ein wichtiger, oben bereits angedeuteter Schwachpunkt der antikörperbasierten Erkennung besteht darin, dass das Zielantigen auf der Zelloberfläche präsent sein muss, während die meisten TSA und TAA nur intrazellulär exprimiert werden. Solche im Innern der Zelle vorhandenen Proteine gelangen jedoch ebenfalls auf die Zelloberfläche, sie werden den Immunzellen in Form kleiner „Proteinschnipsel“ (Peptide) durch den sog. Histokompatibilitätskomplex (MHC) präsentiert. ${ }^{27}$ Bevor sie auf Patrouille geschickt werden, durchlaufen Immunzellen eine Trainingsphase, sodass sie „eigene“ Epitope, also solche, die in gesunden Körperzellen exprimiert werden, von „fremden“ unterscheiden können. Fremd steht somit entweder für eine Infektion (z. B. durch ein Virus) oder für ein defektes, potenziell gefährliches (z. B. krebsauslösendes) Protein. Zur Erkennung der vom MHC präsentierten Epitope verfügt jede T-Zelle über ihren individuellen, hochspezifischen TCR. Es gilt das Prinzip, dass ein TCR genau ein Epitop erkennt. Findet eine T-Zelle über ihren TCR ein fremdes und somit bedrohliches Epitop, fängt sie an, sich stark zu vermehren, um dann alle Zellen anzugreifen, die dieses Epitop tragen. Wenn alles re-

26 TRUCK steht für „T cells Redirected for Universal Cytokine-mediated Killing“.

27 Der MHC („Major histocompatibility complex“; beim Menschen auch HLA, „Human Leukocyte antigen“) bildet den Haupt-Gewebeverträglichkeitskomplex (auch „Transplantationsantigene“), markiert also alle unsere Zellen als „selbst“ (self). Für die Erkennung sind zwei Klassen von MHCMolekülen (MHC I und MHC II) wichtig. Zur Erkennung von „selbst“ und „fremd“ präsentieren die MHC-Moleküle kleine Ausschnitte aller in der Zelle gebildeten Proteine auf der Zelloberfläche. In der präsentierten Form werden besagte Abschnitte „Epitope“ genannt. 
gelgerecht funktioniert, werden alle mit dem entsprechenden Virus infizierten Zellen oder eben alle Tumorzellen, die das mutierte, krebsfördernde Gen tragen, abgeräumt. Allerdings haben sowohl Viren als auch Krebszellen Mechanismen entwickelt, um diese Immunreaktion zu verhindern oder soweit möglich zu unterdrücken. So können Krebszellen z. B. sog. Checkpoint-Signale auf ihrer Oberfläche tragen, die den Immunzellen vermitteln, dass die Immunreaktion jetzt ausgereicht hat und sie ihre Aktivität einstellen können. Sie nutzen so einen wichtigen Bremsmechanismus des Immunsystems, der normalerweise dazu dient, überschießende Immunreaktionen zu verhindern. ${ }^{28}$

Schon seit Längerem wurde auf verschiedenen Wegen versucht, tumorspezifische T-Zellen für die Bekämpfung von Krebserkrankungen nutzbar zu machen. So wurden Immunzellen aus Tumoren isoliert (sog. Tumor-infiltrierende Lymphozyten, TIL) und dann außerhalb des Körpers vermehrt, um in Abwesenheit der negativen Einflüsse des Tumormikromilieus eine ausreichende Anzahl an möglichst aktiven T-Zellen zu generieren. Der nächste logische Schritt war, die T-Zellen von Patienten zu isolieren, die eine effiziente Immunantwort gegen ihren Tumor entwickelt hatten. Die Idee bestand darin, aus diesen Zellen den einmal erfolgreichen TCR zu isolieren und mithilfe geeigneter Genfähren auf die T-Zellen anderer Patienten zu übertragen. Dies ist, sehr kurz zusammengefasst, das Prinzip der TCR-Gentherapie. Da spezifische TCRs, wie bereits ausgeführt, auch Krebsantigene (TSAs und TAAs) erkennen können, ergeben sich viel mehr potenzielle Angriffspunkte als bei den CARs. Allerdings ist es für den Erfolg des TCR-Ansatzes essenziell, dass die Zielepitope von den passenden MHC-Molekülen korrekt präsentiert werden, damit sie von den T-Zellen erkannt werden. Daraus ergibt sich, dass ein Antitumor-TCR nur dann auch bei einem anderen Patienten funktioniert, wenn bei Letzterem das anvisierte Epitop vom gleichen MHC-Molekül präsentiert wird wie bei dem Patienten, aus dem der TCR ursprünglich isoliert wurde. Bekanntlich ist die Gesamtheit der MHC-Moleküle bei jedem Menschen individuell, sie wird zur Hälfte von der Mutter und zur Hälfte vom Vater geerbt. ${ }^{29}$ (Wie) Kann das dann überhaupt funktionieren? Zum Glück ist die Zahl immunologisch unterschiedlicher Varianten

28 James Allison und Tasuku Honjo konnten zeigen, dass man Immunzellen wieder gegen die Tumorzellen scharfmachen kann, indem man den Bremsmechanismus durch die gezielte Blockade solcher Checkpoints (CTLA-4 und PD-1) über Antikörper wieder ausschaltet. Sie begründeten so eine neue Klasse effizienter, immuntherapeutischer Krebsmedikamente („Checkpoint-Inhibitoren“), wofür sie 2018 den Nobelpreis für Medizin erhielten.

29 Die unterschiedlichen MHC-Moleküle sitzen alle eng zusammen auf Chromosom 6 und werden jeweils „am Stück“ vererbt. Hat der Vater z. B. (vereinfacht) die Varianten A und B, die Mutter C und D, so können die Kinder eine der folgenden Varianten erben: AC, AD, BC, BD. Entsprechend beträgt die Wahrscheinlichkeit, dass ein Geschwister die gleichen Gewebemerkmale hat $25 \%$ (1:4). Dies ist z. B. bei der Suche nach einem passenden Spender für eine Stammzelltransplantation wichtig. 
(„Serotypen“) für den MHC-Komplex begrenzt - die große Variabilität wird dadurch erreicht, dass sie bei jedem Einzelnen in unterschiedlichen Kombinationen vorkommen. Manche MHC-Moleküle sind sogar recht häufig anzutreffen, z. B. findet man den Serotyp HLA-A*02 bei recht vielen Menschen. ${ }^{30}$ Genau diese häufigen HLA-Varianten sind für die TCR-Immuntherapie interessant, weil von einem HLA-A*02-spezifischen TCR prinzipiell sehr viele Patienten profitieren könnten, deren Krebszellen die Mutation aufweisen, welche der TCR erkennt.

Neben dieser MHC-Restriktion steht die TCR-Gentherapie vor einigen weiteren praktischen Herausforderungen. Der TCR besteht aus zwei Ketten ( $\alpha$ und $\beta$ oder $\gamma$ und $\delta$ ), die beide in die Zielzelle eingebracht und dort in großer Zahl und zugleich in einem ausgewogenen Verhältnis exprimiert werden müssen. Dafür mussten geeignete Gentaxis entwickelt werden. Ein grundsätzliches Problem der TCR-Ansätze bildet die Tatsache, dass jede T-Zelle ja schon über einen eigenen „endogenen“ TCR verfügt. Bringt man in eine T-Zelle mit einem $\alpha$-/ $\beta$-TCR je noch eine $\alpha$ - und $\beta$-Kette, kann es zu Fehlpaarungen kommen, wodurch neue TCRs mit unbekannter Spezifität entstehen können. Da die beiden Ketten ( $\alpha$ und $\beta$ ) sehr genau zueinander passen müssen, damit ein funktioneller TCR entsteht, sind die meisten Fehlpaarungen folgenlos. In seltenen Fällen können aber TCRs entstehen, die autoreaktiv sind, sich also gegen den eigenen Körper richten. ${ }^{31}$ Inzwischen lassen sich die Techniken des Genome-Editing anwenden, um den endogenen TCR auszuschalten und somit Fehlpaarungen vollständig auszuschließen (Berdien et al., 2014; Knipping et al., 2017).

Trotz der genannten Probleme bei der klinischen Umsetzung wurden (und werden) bereits TCR-basierte Immuntherapien gegen eine ganze Reihe krebsassoziierter Antigene klinisch getestet - im internationalen Studienregister clinicaltrials.gov finden sich nahezu 100 (aktuelle wie auch beendete) Studien zum TCR-Gentransfer. In verschiedenen Studien wurden TCRs gegen unterschiedlichste tumorassoziierte Antigene zur Behandlung verschiedener Krebserkrankungen eingesetzt. Auch zur Behandlung lebensbedrohlicher Infektionen (Epstein-Barr-Virus [EBV], Cytomegalievirus [CMV]), zumeist im Kontext von Transplantationen, kamen (virusspezifische) TCRs zum Einsatz. ${ }^{32}$ Wie bei den CARs findet die große Mehrheit aller TCR-Studien in den USA und China statt. In Europa befinden sich Schwerpunkte u. a. in England und den Niederlanden, aber

30 Eigentlich steht der Serotyp HLA-A*02 für Hunderte verschiedener Allelvarianten, die sich aber immunologisch kaum unterscheiden und i. d. R. gegenseitig nicht abstoßen.

31 Eine aufsehenerregende Arbeit unter Beteiligung deutscher Wissenschaftler konnte im Jahr 2010 zeigen, dass solche fehlgebildeten TCRs im schlimmsten Fall eine tödliche Transplantat-gegen-Empfänger-Reaktion auslösen können (Bendle et al., 2010).

32 Siehe unter: https://clinicaltrials.gov [01.03.2021]; Suchbegriffe „TCR“ und „T cell receptor“. 
auch mehrere deutsche Forscher (u. a. Thomas Blankenstein, Matthias Leisegang, Dolores Schendel und Wolfram Uckert) haben über viele Jahre in diesem Feld gearbeitet. Basierend auf den Arbeiten der genannten wie auch einer Reihe anderer Wissenschaftler engagieren sich inzwischen auch mehrere deutsche Firmen bei der klinischen Umsetzung der TCR-Gentherapie, wobei sich die meisten Studien allerdings noch in frühen Phasen befinden. Zu nennen wären $u$. a. die Firmen Medigene (München) und immatics (Tübingen), die jeweils mehrere eigene TCR-basierte Immuntherapien in klinischer Testung haben. Auch BioNTech (Mainz) verfolgt verschiedene TCR-Strategien.

Insgesamt lassen sich also im Bereich der adoptiven (zellulären) Immuntherapien Fortschritte auf breiter Front konstatieren. Bei aller Euphorie darf aber nicht vergessen werden, dass sich deren Anwendung in den meisten Fällen noch in der klinischen Testung befindet und auf einen sehr kleinen Kreis von Patienten beschränkt. Einer der wichtigsten Gründe dafür besteht darin, dass es sich in aller Regel um individualisierte Therapien handelt, die für jeden einzelnen Patienten extra hergestellt werden müssen. ${ }^{33}$ Dies ist nicht nur teuer, ${ }^{34}$ sondern auch zeitaufwendig, was insbesondere bei schnell fortschreitenden Erkrankungen problematisch ist. Zudem müssen Zellen von Patienten genutzt werden, die oft schon stark vorbehandelt sind, worunter auch die Funktionalität der Immunzellen gelitten haben kann. Um diesen Limitationen zu begegnen, wird versucht, mithilfe des Genome-Editing sog. „universelle“ CAR-T-Zellen herzustellen. ${ }^{35}$ Diese Zellen stammen von einem gesunden Spender und können für mehrere Patienten genutzt werden; sie stehen bei Bedarf also sofort zur Verfügung und sind zudem „fitter“, weil sie im Gegensatz zu den patienteneigenen Zellen keinen Chemotherapien ausgesetzt waren. ${ }^{36} \mathrm{Um}$ solche universellen Zellen zu generieren werden in den Spender-T-Zellen zum einen die Gewebeverträglichkeitsantigene (MHC, siehe oben) ausgeschaltet, damit die Zellen nicht unmittelbar vom Empfänger abgestoßen werden. Außerdem wird der endogene TCR ausgeknockt (siehe Berdien et al., 2014; Knipping et al., 2017), um umgekehrt eine Reaktivität der infundierten T-Zellen gegen die für sie „fremden“ Gewebe des Empfängers („,Spender-gegen-Wirt-Reaktion“) zu verhindern. Eine erste klinische Studie mit universellen CD19-CAR-T-Zellen, die in London durchgeführt wurde, basierte auf der TALEN-Technologie, einer alternativen, etwas früheren Methode des Genome-Editing (Qasim et al., 2017). Inzwischen testet die US-

33 Dies gilt sowohl für CAR-als auch für TCR-basierte Ansätze.

34 Oft wird eine Kostenübernahme im Rahmen von Einzelfallentscheidungen der Kassen entschieden.

35 Nicht zu verwechseln mit den universellen CAR-Konstrukten (siehe Fußnote 21).

36 Dafür hat sich die englische Redewendung „off-the-shelf“ („direkt vom Regal“ bzw. „ab Lager“) eingebürgert. 
Firma CRISPR Therapeutics universelle CAR-T-Zellen mit verschiedenen CAR-Konstrukten. ${ }^{37}$ Alternativ wird auch versucht, statt der T-Lymphozyten genetisch modifizierte „Natural Killer“-Zellen (NK) für die Immuntherapie zu nutzen. Auch mit CAR-NK-Zellen laufen bereits eine Reihe (früher) klinischer Studien (siehe z. B. Liu et al., 2020). Wie die universellen CAR-T-Zellen sind CAR-NK-Zellen bei Bedarf „off-the-shelf“ verfügbar.

Eine andere Möglichkeit, die Herstellung individueller Zellpräparate zu umgehen, besteht darin, die T-Zellen direkt im Körper scharf zu stellen. Zu diesem Zweck können die T-Zellen z. B. im Körper des Patienten (in vivo) mit geeigneten CAR- bzw. TCR-Konstrukten genetisch modifiziert werden. Hierfür müssen spezielle Vektoren entwickelt werden, die die CARs oder TCRs ausschließlich in die T-Zellen des Patienten einbauen. Führende Arbeiten auf diesem Gebiet, welches sich noch in der präklinischen Entwicklung befindet, stammen von der Gruppe um Christian Buchholz (siehe z. B. Pfeiffer et al., 2018).

Der alternative Ansatz der Aktivierung einer krebsspezifischen Immunantwort im Patienten durch Vakzinierung mit krebsspezifischer mRNA wurde bereits oben kurz angesprochen. Im ersten Schritt werden anhand einer Probe (Biopsie) der Tumorzellen krebsspezifische Mutationen identifiziert. Dazu macht man sich die neue Hochdurchsatzsequenzierung ${ }^{38}$ zunutze. Interessant sind vor allem solche Mutationen, die in allen oder nahezu allen Tumorzellen vorkommen. Anhand des genetischen Codes werden solche Mutationen ausgewählt, die zu Änderungen in kodierten Proteinen in den Krebszellen führen. Schließlich können mithilfe bioinformatischer Methoden jene Proteinveränderungen identifiziert werden, die in dem jeweils betroffenen Patienten mit hoher Wahrscheinlichkeit eine Immunantwort hervorrufen werden. Für die (z. B. 10) besten Kandidaten werden mRNA hergestellt, die zu einem patientenspezifischen Vakzin vermischt werden. Dieser Ansatz ist es, an dem Uğur Şahin und Özlem Türeci seit Jahren forschen (Sahin et al., 2014; Kreiter et al., 2015; Sahin/Türeci, 2018) und den sie mit ihrer Firma BioNTech erfolgreich in vielversprechende klinische Studien überführt haben (Sahin et al., 2017). Während solche personalisierten Ansätze sehr aufwendig sind, kann die mRNA-Technologie auch dazu genutzt werden, breit anwendbare Vakzinierungen gegen häufige TAAs zu entwickeln, oder sogar die Aktivität von CART-Zellen zu verstärken (Reinhard et al., 2020; Sahin et al., 2020). Dass die Technologie schließlich auch zur schnellsten Impfstoffentwicklung gegen ein pandemisches Virus

37 Die Klinik für Stammzelltransplantationen des UK Hamburg-Eppendorf nimmt als einziges europäisches Zentrum an der „CARBON“-Studie mit universellen CD19-CAR-T-Zellen zur Behandlung rezidivierender bzw. refraktärer B-Zell-Krebserkrankungen teil. Siehe unter: https://clinicaltrials.gov/ ct2/show/NCT04035434 [10.02.2021].

38 „Next-generation sequencing“ (NGS) (siehe Mundlos, Kap. 4). 
in der Geschichte führen würde, kam wahrscheinlich auch für die beiden Tumorimmunologen überraschend.

\subsubsection{Direkte Tumorzerstörung}

Während die oben beschriebene zellbasierte Immuntherapie sich quasi von hinten an den Tumor anschleicht (und zumindest derzeit noch sehr aufwendig ist), zielen die im Folgenden beschriebenen Strategien unmittelbar auf die (möglichst hochspezifische) Zerstörung der Tumorzellen. Bereits in den 1990er Jahren wurden dafür sog. Suizidgenansätze ${ }^{39}$ entwickelt, die es sogar in die Phase-III-Testung zur Behandlung des Glioblastoms (ein unheilbarer Hirntumor) schafften. Der klinische Misserfolg einer relativ großen Phase-III-Studie von Novartis (Stein et al., 2010) trug dazu bei, dass sich „Big Pharma“ seinerzeit praktisch vollständig aus der Gentherapie zurückzog. Trotzdem wird der Suizidgenansatz gerade für häufig inoperable oder nicht komplett resektierbare Tumoren wie das Glioblastom auch heute noch, mit optimierten Suizidgenen und Vektoren, weiterverfolgt. ${ }^{40}$

Ein anderer klinischer Ansatz beruhte darauf, in die malignen Zellen eine korrekte Kopie des in fast allen menschlichen Tumoren mutierten TP53-Gens einzubringen. Als sog. Tumorsuppressor hat das p53 genannte Protein eine zentrale Wächterfunktion, verhindert also normalerweise die Vermehrung bösartiger Zellen, sodass diese erst möglich wird, wenn das TP53-Gen durch Mutationen inaktiviert ist. Wird in die Tumorzellen erneut eine funktionale Genkopie eingebracht, stoppt die unkontrollierte Zellteilung, die Zellen sterben ab oder differenzieren in normales Gewebe. Es war eine internationale Sensation, als im Jahr 2003 in China adenovirale TP53-Vektoren als weltweit erstes kommerzielles Gentherapieprodukt (Gendicine ${ }^{\circledast}$ ) zugelassen wurden. ${ }^{41} \mathrm{Nach}$ einer jüngeren Arbeit wurden in den ersten 12 Jahren nach der Zulassung in China mit dem Vektor $>30.000$ Patienten behandelt und $>30$ klinische Studien durchgeführt. Laut der zitierten Arbeit (Zhang et al., 2018) zeigte Gendicine ${ }^{\circledast}$ ein exzellentes Sicherheitsprofil und erzielte, in Kombination mit Chemo- und Radiotherapie, ein deutlich verbessertes Langzeitüberleben, nicht nur bei Kopf-Hals-Tumoren, sondern auch bei einer Reihe anderer Krebsarten.

39 Suizidgene lösen den programmierten Zelltod aus, auch Apoptose genannt. Das bedeutet, dass die Zellen kontrolliert absterben.

40 Siehe u. a. Hossain et al. (2019); Übersicht z. B. in Hossain et al. (2020).

41 Zulassung durch die China Food and Drug Administration (CFDA) auf Antrag von Shenzhen SiBiono GeneTech Co für die Indikation Kopf-Hals-Tumoren, der kommerzielle Markteintritt erfolgte 2004. 
Allerdings ist der Erfolg beider oben beschriebener Konzepte dadurch limitiert, dass der therapeutische Vektor zumindest theoretisch jede Tumorzelle (inkl. bereits gestreuter Metastasen) erreichen müsste, um eine Rückkehr des Tumors zu verhindern. ${ }^{42}$ Eine Lösung dieses Problems versprechen sog. konditionell replizierende, ${ }^{43}$ onkolytische Viren. Diese Viren können sich nur in Krebszellen vermehren, wobei sie diese im Zuge ihrer Vermehrung zerstören („lysieren“). Um Viren tumorspezifisch zu machen, kann man verschiedene Besonderheiten der Krebszellen ausnutzen, wie z. B. die oben beschriebenen häufig anzutreffenden Mutationen in TP53 oder auch den für die erhöhte Teilungsrate umgestellten Stoffwechsel. Der Ansatz beruht also darauf, einen (Wachstums-)Vorteil der Krebszellen in eine Achillesferse umzuwandeln. Entsprechend basierte das erste, bereits in den 1990er Jahren in den USA entwickelte onkolytische Viren-Therapeutikum (ONYX015) darauf, dass das genutzte Adenovirus genetisch so modifiziert worden war, dass es das p53-Protein nicht mehr binden konnte (Heise et al., 1997). Damit konnte das Virus zwar weiterhin in alle Zellen eindringen, sich aber nicht mehr in normalen, sondern eben nur noch in p53-negativen, also Krebszellen, vermehren. Dies illustriert das selbstlimitierende Grundprinzip der onkolytischen Viren - solange noch Tumorzellen im Körper sind, können sich die Viren vermehren und diese zerstören. Leider wird dieser, in der Theorie quasi perfekte Therapieansatz, vor allem dadurch konterkariert, dass das Immunsystem des Patienten seine Aufgabe erfüllt und die replizierenden Viren als Eindringlinge erkennt und zerstört. Nicht zuletzt dies war der Grund, dass die klinische Testung des ersten onkolytischen Virus ONYX015 weniger erfolgreich verlief als erwartet, insbesondere, da für die Herstellung des Virus ein weit verbreiteter Serotyp (AdV5) ${ }^{44}$ genutzt wurde, gegen den viele Patienten bereits vorab immunisiert waren (Kirn, 2001). Überraschend wurde ein praktisch identisches onkolyisches Virus im Jahr 2005, d. h. kurze Zeit nach dem Abbruch der Entwicklung in den USA, unter dem Namen Oncorine ${ }^{\circledast}$ als weltweit zweites Gentherapeutikum in der VR China kommerziell zugelassen. Initiale Reporte chinesischer Autoren berichteten

42 Um diese Aufgabe zu erleichtern, werden die Gentherapien wie beschrieben mit klassischen Krebstherapien (Chemo, Bestrahlung) kombiniert; trotzdem bleibt das Problem bestehen, dass zum Zeitpunkt der Behandlung nicht alle Zellen erreicht werden können. Um einen andauernden Therapieerfolg zu erreichen, setzt man darauf, dass die Zerstörung eines Großteils der Tumorzellen zu einer Aktivierung tumorspezifischer Immunzellen führt, die die verbliebenen malignen Zellen abtöten.

43 „Konditionell replizierend“ bedeutet, dass bestimmte Bedingungen zwingend vorliegen müssen, damit sich das Virus vermehren kann.

44 Adenoviren sind typische Erreger von „grippalen“ Infekten beim Menschen; der Serotyp definiert ein bestimmtes Virus aus der besagten Virusfamilie. Zuletzt wurden adenovirale Vektoren im Kontext der Vektorimpfstoffe (AstraZeneca, Johnson \& Johnson, Sputnik) gegen SARS-CoV2 weithin bekannt. 
von deutlich besseren klinischen Resultaten (Liang, 2012), was damit zusammenhängen könnte, dass der AdV5-Serotyp in China wesentlich seltener zu sein scheint. Nach einer aktuelleren Übersichtsarbeit scheint die Entwicklung von Oncorine ${ }^{\circledast}$ allerdings recht schnell nach der Markteinführung weitgehend eingestellt worden zu sein (Liang, 2018).

Glücklicherweise führte der mangelnde Erfolg des ersten onkolytischen Virus nicht dazu, dass das ganze Konzept infrage gestellt wurde. Stattdessen wurde eine Reihe sehr unterschiedlicher Virusarten genetisch so modifiziert, dass möglichst effiziente und spezifische onkolytische Viren resultieren. Die Spezifität wird dabei nicht nur über die Anpassung an die oben eingeführten Achillesfersen der Krebszellen erreicht, sondern zusätzlich z. B. dadurch, dass die Viren gezielt nur noch bestimmte Zellen, z. B. sog. Krebsstammzellen, infizieren können (Bach et al., 2013). Zudem bringen moderne onkolytische Viren zusätzlich stimulierende Faktoren, z. B. geeignete Botenstoffe, in die Krebszellen ein, um zusätzlich zu ihrem eigenen tumorlytischen Effekt auch noch Immunzellen zu aktivieren.

Ende 2015 wurde, nach erfolgreichem Abschluss der Zulassungsstudie (Andtbacka et al., 2015), das in den USA entwickelte, vom Herpes simplex Virus abgeleitete onkolytische Virus T-Vec (Imlygic ${ }^{\oplus}$, Firma Amgen) in den USA und Europa zur Behandlung des schwarzen Hautkrebses (malignes Melanom) zugelassen. Eine Reihe weiterer onkolytischer Viren befindet sich in zum Teil weit fortgeschrittener klinischer Testung, sodass mit weiteren Zulassungen in den kommenden Jahren zu rechnen ist. Auch Forscher aus und in Deutschland ${ }^{45}$ haben eine Reihe wichtiger Beiträge zur Entwicklung verschiedener onkolytischer Viren geleistet (Übersicht: Ungerechts et al., 2017).

\subsection{Monogene Erbkrankheiten}

Als sozusagen „natürliches“ Ziel der Gentherapie stellten monogene Erbkrankheiten die ersten Indikationen für gentherapeutische Interventionen dar. Tatsächlich wurde bereits Anfang der 1970er Jahre versucht, angeborene Stoffwechselkrankheiten durch Genersatz zu behandeln. ${ }^{46}$ Auch die erste „offizielle“ Gentherapiestudie 1990 am National Institute of Health der USA zielte auf die Behandlung eines angeborenen Gendefekts, der zu dem schweren Immunmangelsyndrom ADA-SCID ${ }^{47}$ führt. Nicht zuletzt vor

45 Z. B. C. Buchholz, C. Engeland, F. Kühnel, D. von Laer, U. Lauer, M. Mühlebach, D. Nettelbeck, J. Rommelaere und G. Ungerechts.

46 Der weltweit wahrscheinlich erste Gentherapieversuch wurde in Köln durchgeführt. Ausführlich in Fehse et al. (2011).

47 Durch den Mangel an Adenosindeaminase (ADA) verursachte „Severe Combined Immune Deficiency“. 
dem Hintergrund der rasanten Entwicklung der Methoden des Genome-Editing stehen heute Ansätze zur Genkorrektur bei monogenen Erbkrankheiten mehr denn je im Zentrum vieler Forschungsaktivitäten.

Auch die ersten, in der Öffentlichkeit kaum wahrgenommenen klinischen Erfolge der Gentherapie wurden bei der Behandlung schwerer angeborener Immundefizienzen, die unbehandelt meist schon im Teenageralter zum Tod führen, erzielt (Aiuti et al., 2002; Hacein-Bey-Abina et al., 2002). Aus einer dieser Studien resultierte die erste in Europa zugelassene zellbasierte Gentherapie. ${ }^{48}$ Ein Grundprinzip der in den 1990er und 2000er Jahren entwickelten Gentherapien war die Nutzung integrierender retroviraler Vektoren für die genetische Modifikation der Blutstammzellen außerhalb des Körpers (ex vivo). ${ }^{49}$ Entscheidende Grundlagen für die Anwendung retroviraler Vektoren im Rahmen der Gentherapie waren am Hamburger Heinrich-Pette-Institut ${ }^{50}$ von Wolfram Ostertag, Rudi Jaenisch und Mitarbeitern gelegt worden. ${ }^{51}$ Die obligatorische Integration retroviraler Vektoren in das Genom der Zielzellen gewährleistet eine langfristige Wirkung der Gentherapie, da die Genkorrektur auch bei Zellteilungen an die jeweiligen Tochterzellen weitergegeben wird. Leider ist die Integration der Vektoren jedoch nicht steuerbar und kann in seltenen Fällen zur Aktivierung benachbarter (Protoonko-) $G^{6} e^{52}$ führen, was eine unkontrollierte Zellvermehrung auslösen kann. Dies wurde experimentell zuerst in Hamburg als seltene Nebenwirkung im Mausmodell gezeigt (Li et al., 2002; Kustikova et al., 2005), manifestierte sich aber später leider auch in klinischen Studien (Hacein-Bey-Abina et al., 2008; Howe et al., 2008; Stein et al., 2010; Braun et al., 2014). ${ }^{53}$ Auch wenn die in der Folge bei Betroffenen beobachteten Leukämien in fast allen Fällen erfolgreich behandelt werden konnten, müssen solche schweren Nebenwirkungen natürlich soweit möglich ausgeschlossen werden. Inzwischen wurden deutlich verbesserte retrovirale Vektoren (Morgan et al., 2021) entwickelt, sodass das Risiko der Leukämieentstehung in den aktuellen Gentherapiestudien mit Blutstammzellen offensichtlich entscheidend minimiert werden konnte. Interessanterweise nutzt die bisher

48 Strimvelis $^{\circledast}$; die genetische Modifikation der Blutstammzellen erfolgt außerhalb des Körpers.

49 Ausführlicher in Fehse et al. (2011), Fehse/Abramowski (2021).

50 Das Institut erhält einen neuen Namen. Siehe unter: https://www.hpi-hamburg.de/de/aktuelles/ presse/einzelansicht/archive/2021/article/entscheidung-fuer-namensaenderung/?tx_ttnews\%5Bmo nth\%5D=04\&cHash=75945135ac130af813180c6597b6cc48 [21.05.2021].

51 Übersicht in Morgan et al. (2021).

52 Protoonkogene sind normalerweise wachstumsregulierende, aber potenziell krebsauslösende Gene. Deutsche Forscher haben entscheidende Beiträge zur Aufklärung der Mechanismen der Leukämieentstehung geleistet: u. a. Li et al. (2002), Kustikova et al. (2005), Modlich et al. (2005 und 2006), Deichmann et al. (2007), Schmidt et al. (2007), Schwarzwaelder et al. (2007).

53 Ausführlich beschrieben in Fehse et al. (2011). 
einzige (nur in Europa) zugelassene Ex-vivo-Gentherapie (Strimvelis ${ }^{\circledR}$ ) jedoch Vektoren des ursprünglichen Typs. Strimvelis ${ }^{\circledR}$ wird zur Behandlung von ADA-SCID (siehe oben) eingesetzt, es zeigte in den klinischen Studien eine sehr gute Wirksamkeit, ohne dass es über einen Zeitrum von ca. 20 Jahren zur Entstehung der bei der Behandlung anderer Immunmangelkrankheiten beobachteten Leukämien gekommen wäre (Aiuti et al., 2002 und 2007). Jedoch wurde im Oktober 2020 ein erster Leukämiefall berichtet, der zum vorläufigen Stopp der Anwendung von Strimvelis ${ }^{\circledR}$ führte. ${ }^{54}$

Auch die erste Zulassung einer sicherheitsoptimierten, auf lentiviralen Vektoren basierenden Blutstammzellgentherapie (Zynteglo ${ }^{\circledast}$ ) nach erfolgreichen klinischen Studien (Thompson et al., 2018) erfolgte im Jahr 2019 in Europa. Dabei handelt es sich um eine Therapie für bestimmte Formen der $\beta$-Thalassämie. ${ }^{55}$ Allerdings startete die kommerzielle Anwendung offensichtlich erst im Jahr 2021, was auf Probleme bei der Herstellung der Vektoren zurückgeführt wird. Darüber hinaus führt der sehr hohe Preis (ca. 1,8 Mio. US\$ für die einmalige Behandlung) zu andauernden kontroversen Diskussionen. ${ }^{56}$

Neben der Ex-vivo-Modifikation von i. d. R. Blutstammzellen zur Behandlung angeborener Erkrankungen des Blutsystems wurden in den letzten Jahren zunehmende Erfolge bei der Korrektur schwerer monogener Erbkrankheiten in vivo erreicht. Dabei werden die Genvektoren direkt in das zu modifizierende Gewebe oder ins Blut gespritzt, um die Produktion eines fehlenden Proteins in den relevanten Zellen des Körpers zu gewährleisten..$^{57}$ In der unmittelbaren Anwendung ist die In-vivo-Gentherapie somit einfacher, weil die genetische Modifikation nach Applikation der geeigneten Vektoren im Körper quasi von selbst erfolgt, während bei der Ex-vivo-Gentherapie eine aufwendige Zellaufreinigung und -kultivierung in Reinraumlaboren erforderlich ist. Aber auch bei der In-vivo-Anwendung ist es natürlich essenziell, eine ausreichende Anzahl von Zellen genetisch zu korrigieren, um einen therapeutischen Effekt zu erzielen. Da der Prozess in vivo nicht kontrolliert werden kann, müssen klinische Effizienz und Sicherheit durch entsprechend umfangreiche präklinische Studien sichergestellt werden.

54 Siehe unter: https://ir.orchard-tx.com/index.php/news-releases/news-release-details/orchardstatement-strimvelisr-gammaretroviral-vector-based-gene [16.04.2021].

55 Thalassämien liegen Mutationen im Globin-Gen zugrunde, wodurch das Hämoglobin nicht in ausreichender Menge vorliegt. Dies führt zum eingeschränkten Sauerstofftransport durch die roten Blutkörperchen.

56 Am 20.04.2021 kündigte die Firma BlueBird Bio den Rückzug vom deutschen Markt an, da keine Einigung bezüglich der Erstattung der Therapie erzielt werden konnte. Siehe unter: https://www. biopharmadive.com/news/bluebird-withdraw-zynteglo-germany-price/598689/ [Zugriff: 16.04.2021]. 57 Ausführlich in Fehse et al. (2011), Fehse/Abramowski-Mock (2021). 
Für die meisten In-vivo-Anwendungen werden heute Vektoren genutzt, die auf adenoassoziierten Viren (AAV) basieren. AAV-Vektoren sind nicht zuletzt deshalb interessant, weil die Ursprungsviren Menschen zwar infizieren können, aber apathogen sind, also keine Krankheiten auslösen. ${ }^{58}$ Während Wildtypviren häufig (an einer bestimmten Stelle auf Chromosom 19) in das Genom infizierter Zellen integrieren, liegen die abgeleiteten Vektoren in der Regel episomal, d. h. in nicht-integrierter Form, im Zellkern vor. Daraus ergibt sich, dass AAV-Vektoren sich für eine langfristige Genkorrektur nur solcher Zellen eignen, die sich nicht mehr teilen (sog. postmitotische Zellen). ${ }^{59}$

Die erste Zulassung für ein AAV-basiertes gentherapeutisches Arzneimittel wurde durch die Europäische Arzneimittelagentur (EMA) im Jahr 2012 für Glybera ${ }^{\circledR}$ gewährt, das für die Behandlung einer extrem seltenen Erbkrankheit (Lipoproteinlipasedefizienz, LPLD) vorgesehen war. Allerdings erwies sich Glybera ${ }^{\circledR}$ in kommerzieller Hinsicht als Misserfolg - aufgrund der sehr hohen Kosten (ca. $900.000 €$ ), denen ein relativ geringer klinischer Effekt gegenüberstand, kam es offensichtlich nur zu einer einzigen kommerziellen Anwendung. Das Medikament wurde in der Zwischenzeit auch wieder vom Markt genommen.

Ende 2017 wurde in den USA (EMA: Ende 2018) eine AAV-basierte Gentherapie (Luxturna ${ }^{\circledast}$ ) der Firma Spark (außerhalb der USA an Novartis lizenziert) zur Behandlung einer angeborenen degenerativen Netzhauterkrankung, die zu fortschreitender Erblindung führt, zugelassen (Maguire et al., 2019). Da es sich bei der Netzhaut um ein verhältnismäßig kleines Zielgewebe handelt, ist die Vektorproduktion hier kein limitierender Faktor. Trotzdem wurde der Preis mit ca. $400.000 €$ pro Auge sehr hoch angesetzt, was auch hier kritisch diskutiert wurde. Mehrere Autoren verwiesen aber auf ein, nicht zuletzt angesichts fehlender Behandlungsalternativen positives Kosten-NutzenVerhältnis (z. B. Johnson et al., 2019).

Die größten Schlagzeilen im Bereich neuer (Gen-)Therapien machte in den letzten Jahren das Medikament Zolgensma ${ }^{\circledR}$, das für die Behandlung der kindlichen Spinalen Muskelatrophie (SMA) entwickelt wurde. Bei SMA handelt es sich um eine seltene, rezessive Erbkrankheit, bei der es durch den Verlust von Motoneuronen zu einem fortschreitenden Muskelschwund kommt. Kinder, die an sehr schweren Verlaufsformen

58 Deutsche Forscher wie H. Büning, D. Grimm, U. Hacker, M. Hallek, J. Kleinschmidt und M. Trepel haben wichtige Beiträge zur Entwicklung der AAV-Vektoren, insbesondere zum Targeting durch Kapsidmodifikation geleistet (Müller et al., 2003; Perabo et al., 2003). Übersicht: Grimm/Büning (2017), Hacker et al. (2020).

59 Viele Gewebe des Körpers zeigen unter normalen Bedingungen keine oder nur eine sehr geringe Teilungsaktivität, z. B. Nervengewebe, Gehirn oder Leber. Letztere kann aber im Falle der Zerstörung von Lebergewebe das Teilungsprogramm wieder aktivieren, wie schon die alten Griechen wussten (Prometheus!). 
leiden, versterben meist in den ersten Lebensjahren oder müssen beatmet werden, um überleben zu können. Der gentherapeutische Ansatz mit AAV-Vektoren basierte auf akademischen Vorarbeiten $u$. a. in Columbus (Ohio) und Paris zum Ersatz des defekten SMN1-Gens („Survival Motor Neuron“) mithilfe eines AAV9-Vektors (Foust et al., 2010; Dominguez et al., 2011). Die klinische Entwicklung (Foust et al., 2010; Dominguez et al., 2011) erfolgte später unter dem Namen AVXS-101 durch das Start-up Avexis, das im Jahr 2018 für 8,7 Mrd. US\$ von Novartis übernommen wurde. Die Therapie wurde 2019 unter dem Handelsnamen Zolgensma ${ }^{\varpi}$ für die Behandlung von Kindern unter 2 Jahren in den $U_{S A}{ }^{60}$ und später in mehreren anderen Ländern lizenziert (Europa: Mai 2020). Die Zulassung war durch einen Datenmanipulationsskandal bei Avexis überschattet, in dessen Rahmen auch Vorwürfe gegen Novartis erhoben wurden. Die FDA erhielt die Zulassung jedoch aufgrund des nachgewiesenen klinischen Nutzens aufrecht. ${ }^{61}$

Weitere kontroverse Diskussionen löste der Spitzenplatz als teuerstes Arzneimittel der Welt (2,1 Mio. US\$ für eine einmalige Behandlung) aus, bei dem sich Novartis u. a. auf die Kosten für das bis dahin einzig zugelassene, im Vergleich weniger wirksame Medikament Spinraza ${ }^{\oplus}$ berief. ${ }^{62}$ Allen Diskussionen zum Trotz war die Nachfrage bei Betroffenen verständlicherweise sehr groß. Zusammen mit Herstellungsproblemen für die sehr großen Mengen an benötigtem Vektor führte dies dazu, dass Novartis die Therapie anfangs nur in begrenztem Umfang bereitstellen konnte. Vor diesem Hintergrund kam es zu einem internationalen Aufschrei, ${ }^{63}$ als Novartis Ende 2019 ankündigte, 100 Dosen von Zolgensma ${ }^{\circledR}$ für Betroffene außerhalb der US-Zulassung über ein Losverfahren zur Verfügung zu stellen. ${ }^{64}$

Auf der Basis exzellenter Studiendaten (Nathwani et al., 2014; George et al., 2017) war auch die Zulassung einer ersten AAV-Vektor-basierten Gentherapie zur Behandlung der Hämophilie B, einer Form der Bluterkrankheit, durch die FDA bereits für 2020

60 Danach ist der therapeutische Effekt nur noch gering.

61 Siehe unter: https://www.fda.gov/news-events/press-announcements/statement-data-accuracyissues-recently-approved-gene-therapy [22.04.2021].

62 Spinraza beruht ebenfalls auf gentechnischen Methoden (sog. Oligonukleotiden, d. h. kurzen DNA-Abschnitten), ist aber formal keine Gentherapie. Es muss lebenslang gegeben werden und kostet im ersten Anwendungsjahr ca. $600.000 €$, danach $300.000 € / \mathrm{Jahr}$.

63 Siehe unter: https://en.wikipedia.org/wiki/Onasemnogene_abeparvovec [22.04.2021].

64 Da viele der Kinder bereits in den ersten beiden Lebensjahren versterben oder beatmungspflichtig werden (und auch die Zulassung nur für Kinder bis 2 Jahre gültig ist), hatten die meisten Betroffenen keine Zeit, auf die Zulassung zu warten. Es gibt aber auch Ethiker, die das Losverfahren angesichts der Umstände als das wahrscheinlich bestmögliche bezeichneten. Siehe unter: https://en.wikipedia.org/ wiki/Onasemnogene_abeparvovec [22.04.2021]. 
erwartet worden. Allerdings hat sich das Zulassungsverfahren verzögert und wird frühestens 2022 abgeschlossen sein. ${ }^{65}$

Zusammengefasst wurden mit AAV-Vektoren große Fortschritte bei der Behandlung monogen verursachter Erbkrankheiten erreicht - bis heute wurden nur AAV-basierte Verfahren für In-vivo-Gentherapien lizenziert. Unerwarteter Weise wurde im Zuge der breiten klinischen Anwendung dieser Vektoren allerdings auch eine Reihe zum Teil schwerster Nebenwirkungen beobachtet. So entwickelten fünf (von mehr als 800 behandelten) Patienten nach Behandlung mit Zolgensma ${ }^{\circledast}$ thrombotische Mikroangiopathien, eine gefährliche Gefäßverschlusserkrankung, die bei einem Patienten leider tödlich endete. ${ }^{66}$ Zudem war die Applikation hoher Dosen der AAV-Vektoren bei verschiedenen Muskelerkrankungen in mehreren Fällen mit schwerer akuter Toxizität (überschießende Immunreaktionen oder Leberdysfunktionen) verbunden. Auch kam es nach sehr vielversprechenden Ergebnissen in der niedrigeren Dosisgruppe einer Studie zur Behandlung einer lebensbedrohlichen Reifungsstörung der Muskeln (Myotubuläre Myopathie) durch AAV-vermittelten Transfer des defekten Myotubularin-1-Gens bei zwei von drei Studienpatienten in der nächsthöheren Dosisgruppe ${ }^{67} \mathrm{zu}$ massiven Leberschäden, die in der Folge zum Tod der Patienten führten (No authors, 2020).

Schließlich steht der Konflikt hinsichtlich des potenziellen Risikos der Entstehung von Leberkrebs als Folge der ungewollten und zufälligen Integration der AAV-Vektoren weiter im Raum (Donsante et al., 2007). Auch wenn dieses Risiko oft in Frage gestellt wird, unterstützen neuere präklinische Studien sowohl im Maus- als auch im Großtiermodell, dass es sich um ein definitives Risiko handelt (Dalwadi et al., 2021). ${ }^{68}$ Dies unterstreicht die Wichtigkeit umfassender präklinischer und klinischer Studien für eine detaillierte Risiko-Chancen-Abwägung.

Vielfach wird das Genome-Editing als mögliche, potenziell wirksamere und sicherere Alternative für die In-vivo-Genkorrektur angesehen. Allerdings müssen auch die Komponenten des Genome-Editing mithilfe geeigneter Vektoren an die richtige Stelle im Körper gebracht werden. Auch hier sind also umfassende Studien notwendig, um effiziente Therapien entwickeln zu können. Da aus Platzgründen eine umfassende Dis-

65 Siehe unter: https://abcnews.go.com/Health/wireStory/fda-blocks-anticipated-biomarin-hemophilia-gene-therapy-72469954 [22.04.2021].

66 Siehe unter: https://www.pei.de/SharedDocs/Downloads/DE/newsroom/veroeffentlichungenarzneimittel/rhb/21-03-18-rhb-zolgensma-onasemnogen-abeparvovec.pdf?__blob=publicationFile\&v=3 [28.04.2021].

67 In der ersten Dosisgruppe wurden $1 \times 10^{14}$ Vektorgenome pro kg verabreichtet, in der zweiten eine (nur) dreimal höhere Dosis.

68 Siehe unter: https://www.sciencemag.org/news/2020/01/virus-used-gene-therapies-may-posecancer-risk-dog-study-hints [22.04.2021]. 
kussion der Chancen und Herausforderungen des klinischen Genome-Editing hier nicht möglich ist, sei auf eine aktuelle Publikation zu diesem Thema verwiesen (Fehse/Abramowski-Mock, 2021; siehe Fehse et al., Kap. 9).

\subsection{Zusammenfassung}

Wie oben an einigen Beispielen dargestellt, hat die somatische Gentherapie in den letzten Jahren einen sehr starken Aufschwung erlebt, der sich nicht zuletzt in der $\mathrm{Zu}$ lassung einer Reihe von Produkten manifestiert hat. Angesichts auf breiter Front weit fortgeschrittener, erfolgreicher klinischer Studien ist auch in den nächsten Jahren mit weiteren Zulassungen sowohl im Bereich der Krebsgentherapie (Immuntherapie, onkolytische Viren) als auch bei der Behandlung monogener Erbkrankheiten zu rechnen. Allerdings spielt sich die aktuelle Entwicklung hauptsächlich in den USA und China ab, Europa im Allgemeinen und Deutschland im Besonderen wurden weitgehend abgehängt. Darin spiegelt sich sowohl der größere Aufwand für die Durchführung klinischer Studien als auch die zurückhaltende Finanzierung derselben in Europa wider. Besagte Entwicklung ist umso ärgerlicher, als dass deutsche Forscher auf vielen Gebieten essenzielle Beiträge zum Fortschritt der Gentherapie geleistet haben bzw. aktuell leisten. Um umfassender von den Früchten dieser Arbeiten profitieren zu können, müssten neue Strukturen und Finanzierungsinstrumente geschaffen werden.

\subsection{Literaturverzeichnis}

Aiuti, A. et al. (2002): Correction of ADA-SCID by stem cell gene therapy combined with nonmyeloablative conditioning. In: Science 296: 2410-2413.

Aiuti, A. et al. (2007): Multilineage hematopoietic reconstitution without clonal selection in ADASCID patients treated with stem cell gene therapy. In: J Clin Invest 117(8): 2233-2240.

Andtbacka, R. H. et al. (2015): Talimogene laherparepvec improves durable response rate in patients with advanced melanoma. In: J Clin Oncol 33(25): 2780-2788.

Arcangeli, S. et al. (2020): Overcoming key challenges in cancer immunotherapy with engineered T cells. In: Curr Opin Oncol 32(5): 398-407.

Ayuk, F. A. et al. (2019): Chancen und Risiken der CAR-T-Zell-Therapie. In: Hamburger Ärzteblatt 73(10): 30-32. Unter: www.aerztekammer-hamburg.org/files/aerztekammer_hamburg/ueber_ uns/hamburger_aerzteblatt/archiv/haeb2019/haeb_10_2019.pdf [27.01.2021].

Ayuk, F. A. et al. (2021): Axicabtagene ciloleucel in vivo expansion and treatment outcome in aggressive B-cell lymphoma in a real-world setting. In: Blood Advances 5(11): 2523-2527. DOI: 10.1182/ bloodadvances.2020003959.

Bach, P. et al. (2013): Specific elimination of CD133+ tumor cells with targeted oncolytic measles virus. In: Cancer Res. 73(2): 865-874. 
Bendle, G. M. et al. (2010): Lethal graft-versus-host disease in mouse models of T cell receptor gene therapy. In: Nat Med 16(5): 565-570.

Berdien, B et al. (2014): TALEN-mediated editing of endogenous T-cell receptors facilitates efficient reprogramming of $\mathrm{T}$ lymphocytes by lentiviral gene transfer. In: Gene Ther 21(6): 539-548. DOI: 10.1038/gt.2014.26.

Braun, C. J. et al. (2014): Gene therapy for Wiskott-Aldrich syndrome-long-term efficacy and genotoxicity. Sci Transl Med. 6(227): 227ra33. DOI: 10.1126/scitranslmed.3007280.

Chmielewski, M./Abken, H. (2015): TRUCKs: the fourth generation of CARs. In: Expert Opin Biol Ther 15(8): 1145-1154.

Dalwadi, D. A. et al. (2021): Liver Injury Increases the Incidence of HCC following AAV gene therapy in mice. In: Mol Ther 29(2): 680-690.

Day, J. W. et al. (2021): Onasemnogene abeparvovec gene therapy for symptomatic infantile-onset spinal muscular atrophy in patients with two copies of SMN2 (STR1VE): an open-label, single-arm, multicentre, phase 3 trial. In: Lancet Neurol 20(4): 284-293.

Deichmann, A. et al. (2007): Vector integration is nonrandom and clustered and influences the fate of lymphopoiesis in SCID-X1 gene therapy. In: J Clin Invest 117: 2225-2232.

Dominguez, E. et al. (2011): Intravenous scAAV9 delivery of a codon-optimized SMN1 sequence rescues SMA mice. In: Hum Mol Genet. 20(4): 681-93.

Donsante, A. et al. (2007): AAV vector integration sites in mouse hepatocellular carcinoma. In: Science 317(5837): 477.

Fehse, B./Abramowski-Mock, U. (2021): Anwendung des Genome Editing in der somatischen Gentherapie: Eine Einführung. Springer Fachmedien, Wiesbaden.

Fehse, B./Domasch, S. (2015): Themenbereich somatische Gentherapie: Translationale und klinische Forschung. In: Müller-Röber, B. et al. (Hrsg.): Dritter Gentechnologiebericht. Analyse einer Hochtechnologie. Forschungsberichte der Interdisziplinären Arbeitsgruppen der Berlin-Brandenburgischen Akademie der Wissenschaften, Band 32. Nomos, Baden-Baden: 211-308.

Fehse, B. et al. (2011): Stand wissenschaftlicher und medizinischer Entwicklungen. In: Domasch, S./ Fehse, B. (Hrsg.): Gentherapie in Deutschland. Eine interdisziplinäre Bestandsaufnahme. Forum W, Dornburg: 31-40.

Foust, K. D. et al. (2010): Rescue of the spinal muscular atrophy phenotype in a mouse model by early postnatal delivery of SMN. In: Nat Biotechnol 28(3): 271-274.

Fredrickson, D. S. (1991): Asilomar and recombinant DNA. The end of the beginning. In: Biomedical Politics: 258-292.

Gagelmann, N. et al. (2020): Development of CAR-T cell therapies for multiple myeloma. In: Leukemia 34(9): 2317-2332.

George, L. A. et al. (2017): Hemophilia B gene therapy with a high-specific-activity factor IX variant. In: N Engl J Med 377(23): 2215-2227. DOI: 10.1056/NEJMoa1708538.

Grimm, D./Büning, H. (2017): Small but increasingly mighty: Latest advances in AAV vector research, design, and evolution. In: Hum Gene Ther 28(11): 1075-1086.

Gross, G. et al. (1989): Expression of immunoglobulin-T-cell receptor chimeric molecules as functional receptors with antibody-type specificity. In: Proc Natl Acad Sci U S A. 86(24): 10024-10028. 
Grupp, S. A. et al. (2013): Chimeric antigen receptor-modified T cells for acute lymphoid leukemia. In: N Engl J Med 368(16): 1509-1518.

Hacein-Bey-Abina, S. et al. (2008): Insertional oncogenesis in 4 patients after retrovirus-mediated gene therapy of SCID-X1. In: J Clin Invest 118: 3132-3142.

Hacker, U. T. et al. (2020): Towards clinical implementation of adeno-associated virus (AAV) vectors for cancer gene therapy: Current status and future perspectives. In: Cancers 12(7): 1889. DOI: 10.3390/cancers12071889.

Heise, C. et al. (1997): ONYX-015, an E1B gene-attenuated adenovirus, causes tumor-specific cytolysis and antitumoral efficacy that can be augmented by standard chemotherapeutic agents. In: Nat Med 3(6): 639-645.

Hossain, J. A. et al. (2019): Long-term treatment with valganciclovir improves lentiviral suicide gene therapy of glioblastoma. In: Neuro Oncology 21: 890-900.

Hossain, J. A. et al. (2020): Suicide gene therapy for the treatment of high-grade glioma: Past lessons, present trends and future prospects. In: Neuro-oncology Advances 2: vdaa013.

Howe, S. J. et al. (2008): Insertional mutagenesis combined with acquired somatic mutations causes leukemogenesis following gene therapy of SCID-X1 patients. In: J Clin Invest 118: 3143-3150.

Hucho, F. et al. (2005): Gentechnologiebericht. Analyse einer Hochtechnologie in Deutschland. Forschungsberichte der Interdisziplinären Arbeitsgruppen der Berlin-Brandenburgischen Akademie der Wissenschaften, Band 14. Elsevier Spektrum, München.

Hucho, F. et al. (2018): Vierter Gentechnologiebericht. Bilanzierung einer Hochtechnologie. Forschungsberichte der Interdisziplinären Arbeitsgruppen der Berlin-Brandenburgischen Akademie der Wissenschaften, Band 40. Nomos, Baden-Baden.

Jain, M. D./Davila, M. L. (2018): Concise review. Emerging principles from the clinical application of chimeric antigen receptor T cell therapies for B cell malignancies. In: Stem Cells 36(1): 36-44.

Johnson, S. et al. (2019): Cost-effectiveness of Voretigene Neparvovec-rzyl vs standard care for RPE65Mediated inherited retinal disease. In: JAMA Ophthalmol 137(10): 1115-1123.

Kalos, M. et al. (2011): T cells with chimeric antigen receptors have potent antitumor effects and can establish memory in patients with advanced leukemia. In: Sci Transl Med 3(95): 95ra73.

Kirn, D. (2001): Oncolytic virotherapy for cancer with the adenovirus dl1520 (Onyx-015): results of phase I and II trials. In: Expert Opin Biol Ther 1(3): 525-538.

Knipping, F. et al. (2017): Genome-wide specificity of highly efficient TALENs and CRISPR/Cas9 for T cell receptor modification. In: Mol Ther Methods Clin Dev 4: 213-224.

Kreiter, S. et al. (2015): Mutant MHC class II epitopes drive therapeutic immune responses to cancer. In: Nature 520(7549): 692-696. DOI: 10.1038/nature14426.

Kustikova, O. et al. (2005): Clonal dominance of hematopoietic stem cells triggered by retroviral gene marking. In: Science 308: 1171-1174.

Lederberg, J. (1967): Dangers of reprogramming cells. In: Science 158(3799): 313.

Lee, D. W. et al. (2019): ASTCT consensus grading for cytokine release syndrome and neurologic toxicity associated with immune effector cells. In: Biol Blood Marrow Transplant 25(4): 625-638.

Li, Z. et al. (2002): Murine leukemia induced by retroviral gene marking. In: Science 296: 497. 
Liang, M. (2012): Clinical development of oncolytic viruses in China. In: Curr Pharm Biotechnol 13: 1852-1857.

Liang, M. (2018): Oncorine, the world first Oncolytic Virus medicine and its update in China. In: Curr Cancer Drug Targets 18(2): 171-176.

Liu, E. et al. (2020): Use of CAR-transduced Natural Killer cells in CD19-positive lymphoid tumors. In: N Engl J Med 382(6): 545-553.

Maguire, A. M. et al. (2019): Efficacy, safety, and durability of Voretigene Neparvovec-rzyl in RPE65 mutation-associated inherited retinal dystrophy: Results of phase 1 and 3 trials. In: Ophthalmology 126(9): 1273-1285.

Mendell, J. R. et al. (2017): Single-dose gene-replacement therapy for Spinal Muscular Atrophy. In: N Engl J Med 377(18): 1713-1722.

Modlich, U. et al. (2005): Leukemias following retroviral transfer of multidrug resistance 1 (MDR1) are driven by combinatorial insertional mutagenesis. In: Blood. 2005 105(11): 4235-4246.

Modlich, U. et al. (2006): Cell-culture assays reveal the importance of retroviral vector design for insertional genotoxicity. In: Blood 108(8): 2545-2553.

Monjezi, R. et al. (2017): Enhanced CAR T-cell engineering using non-viral Sleeping Beauty transposition from minicircle vectors. In: Leukemia 31(1): 186-194.

Moreno-Cortes, E. et al. (2021): Chimeric antigen receptor T cell therapy in oncology - Pipeline at a glance: Analysis of the ClinicalTrials.gov database. In: Crit Rev Oncol Hematol 159: 103239.

Morgan, M. A. et al. (2021): Retroviral gene therapy in Germany with a view on previous experience and future perspectives. In: Gene Ther. DOI: 10.1038/s41434-021-00237-x.

Müller, O. J. et al. (2003): Random peptide libraries displayed on adeno-associated virus to select for targeted gene therapy vectors. In: Nat Biotech 21: 1040-1046.

Müller-Röber, B. et al. (2009): Zweiter Gentechnologiebericht. Analyse einer Hochtechnologie in Deutschland. Forschungsberichte der Interdisziplinären Arbeitsgruppen der Berlin-Brandenburgischen Akademie der Wissenschaften, Band 23. Forum W, Dornburg.

Müller-Röber, B. et al. (2015): Dritter Gentechnologiebericht. Analyse einer Hochtechnologie. Forschungsberichte der Interdisziplinären Arbeitsgruppen der Berlin-Brandenburgischen Akademie der Wissenschaften, Band 32. Nomos, Baden-Baden.

Nathwani, A. C. et al. (2014): Long-term safety and efficacy of factor IX gene therapy in hemophilia B. In: N Engl J Med 371(21): 1994-2004.

Neelapu, S. S. et al. (2017): Axicabtagene ciloleucel CAR T-cell therapy in refractory large B-cell lymphoma. In: N Engl J Med 377(26): 2531-2544.

No authors (2020): High-dose AAV gene therapy deaths. In: Nat Biotechnol 38(8): 910.

Parker, K. R. et al. (2020): Single-cell analyses identify brain mural cells expressing CD19 as potential off-tumor targets for CAR-T immunotherapies. In: Cell 183(1): 126-142.e17.

Perabo, L. et al. (2003): In vitro selection of viral vectors with modified tropism. The adeno-associated virus display. In: Mol Ther 8: 151-157.

Porter et al. (2011): Chimeric antigen receptor-modified T cells in chronic lymphoid leukemia. In: N Engl J Med. 365(8): 725-733.

Pfeiffer, A. et al. (2018): In vivo generation of human CD19-CAR T cells results in B-cell depletion and signs of cytokine release syndrome. In: EMBO Mol Med 10(11): e9158. DOI: 10.15252/ emmm.201809158. 
Prommersberger, S. et al. (2021): CARAMBA: a first-in-human clinical trial with SLAMF7 CAR-T cells prepared by virus-free Sleeping Beauty gene transfer to treat multiple myeloma. In: Gene Ther. DOI: 10.1038/s41434-021-00254-w.

Qasim, W. et al. (2017): Molecular remission of infant B-ALL after infusion of universal TALEN geneedited CAR T cells. In: Sci Transl Med 9(374): eaaj2013. DOI: 10.1126/scitranslmed.aaj2013.

Reinhard, K. et al. (2020): An RNA vaccine drives expansion and efficacy of claudin-CAR-T cells against solid tumors. In: Science 367(6476): 446-453.

Rejeski, K. et al. (2021): CAR-HEMATOTOX: A discriminative model for CAR T-cell related hematotoxicity in relapsed/refractory large B-cell lymphoma.

Sahin, U./Türeci, Ö. (2018): Personalized vaccines for cancer immunotherapy. In: Science 359(6382): 1355-1360.

Sahin, U. et al. (2014): mRNA-based therapeutics - developing a new class of drugs. In: Nat Rev Drug Discov 13(10): 759-80.

Sahin, U. et al. (2017): Personalized RNA mutanome vaccines mobilize poly-specific therapeutic immunity against cancer. In: Nature 547(7662): 222-226.

Sahin, U. et al. (2020): An RNA vaccine drives immunity in checkpoint-inhibitor-treated melanoma. In: Nature 585(7823): 107-112.

Schmidt, M. et al. (2007): High-resolution insertion-site analysis by linear amplification-mediated PCR (LAM-PCR). In: Nat Methods 4: 1051-1057.

Schuster, S. J. et al. (2019): Tisagenlecleucel in adult relapsed or refractory diffuse large B-cell lymphoma. In: N Engl J Med 380(1): 45-56.

Schwarzwaelder, K. et al. (2007): Gammaretrovirus-mediated correction of SCID-X1 is associated with skewed vector integration site distribution in vivo. In: J Clin Invest 117: 2241-2249.

Stein, S. et al. (2010): Genomic instability and myelodysplasia with monosomy 7 consequent to EVI1 activation after gene therapy for chronic granulomatous disease. In: Nat Med. 16(2): 198-204.

Tatum, E. L. (1966): Molecular biology, nucleic acids, and the future of medicine. In: Persp Biol Med 10: $19-32$.

Terheggen, H. G. et al. (1975): Unsuccessful trial of gene replacement in arginase deficiency. In: Z Kinderheilkd. 119(1): 1-3.

Thompson, A. A. et al. (2018): Gene therapy in patients with transfusion-dependent $\beta$-Thalassemia. In: N Engl J Med 378(16): 1479-1493.

Ungerechts, G. et al. (2017): Virotherapy research in Germany: From engineering to translation. In: Hum Gene Ther 28(10): 800-819.

Wagner, J. et al. (2020): CAR T cell therapy for solid tumors: Bright future or dark reality? In: Mol Ther 28(11): 2320-2339.

Zhang W. W. et al. (2018): The first approved gene therapy product for cancer Ad-p53 (Gendicine): 12 Years in the clinic. In: Hum Gene Ther 29(2): 160-179. 